ANTHONY GALE, NAOMI DUNKIN, and MICHAEL COLES, University of Exeter, Exeter, Devon, England

EEG frequency distributions are compared over three viewing conditions: eyes-closed, eyes-open with matt black display, and eyes-open with a patterned display of white geometrical shapes on a black background. The distributions for the three conditions (derived from a total recording time of $24 \mathrm{~min}$ ) may be ranked in accordance with an arousal hypothesis. Integrated output in all measured frequencies is reduced in the more aroused states, and differences between aroused conditions occur within the alpha and subalpha ranges, rather than in the beta range.

The general relationship between stimulus complexity and both behavioral and physiological measures has been explored by Berlyne (1960). When $S$ is instructed to attend carefully to a patterned display for the purpose of a recognition task, incidence of the GSR is greater for more complex or irregular patterns (Berlyne et al, 1963). More complex or incongruous patterns also evoke longer EEG desynchronization than less complex patterns (Berlyne \& McDonnell, 1965). Similar results are obtained by Baker \& Franken (1967) with EEG desynchronization; but they also show that size and brightness of display have no effect. Such desynchronization studies measure short-term responses to stimuli of only brief duration. Continuous and prolonged exposure to monotonous visual stimulation is dearousing (Berlyne, 1960). But again, the degree of dearousal must be dependent upon the complexity of the visual display. Both the dearousing effect of monotony and the differential effects of visual complexity should influence the characteristics of the resting EEG. SUBJECTS

Ten undergraduate students at the University of Exeter with an average age of 21 years served as Ss.

\section{APPARATUS AND PROCEDURE}

The $S$ reclined on a bed in a soundproof cubicle with constant room temperature of $65 \mathrm{deg} F$. The head of the bed was surrounded by a screen of black card, so that $S$ lay with head facing upwards from the lower inner surface of a black cube ( $3 \mathrm{ft}$ square), the nearest surface to the face not being less than 24 in. Constant moderate illumination $\left(8.5 \mathrm{LM} \mathrm{ft}^{2}\right)$ was provided by a hidden bulb giving reflected light through an aperture on the upper edge of the screen. Instructions were given to $S$ through an intercom. Silver/silver chloride pad electrodes were placed transoccipitally for bipolar recording. Interelectrode resistance was always below $5 \mathrm{k}$ ohms. The EEG was recorded on a San'ei polygraph, calibrated to give $24 \mathrm{~mm}$ write-out (peak to trough) for $100 \mu \mathrm{V}$, time constant $0.3 \mathrm{sec}$. Continuous write-out of the voltage output of eight separate band-pass filters, each integrated over an epoch of $5 \mathrm{sec}$, was provided by a San'ei Low Frequency Analyser, calibrated to give a resolution of $40 \times 1 \mathrm{~mm}$ intervals. The following filters were used: $2.0-4.5 \mathrm{cps}, 4.5-6.5 \mathrm{cps}, 7.5-8.5 \mathrm{cps}, 8.5-9.5 \mathrm{cps}$, 9.5-10.5 cps, $10.5-11.5 \mathrm{cps}, 11.5-14.5 \mathrm{cps}$, and $14.5-20 \mathrm{cps}$. Both the primary recording and the integrated output of the analyzer were written out on continuous millimeter graph paper, run at $5 \mathrm{~mm}$ per sec.

Two visual displays ( $22 \times 20.5$ in.) were presented to $S$ : a matt black card display and a patterned display of white overlapping geometrical shapes on a matt black background. Each stimulus was presented for a block of $6 \times 1-\mathrm{min}$ trials, each trial alternated with a 1-min eyes-closed trial, giving a total of $121-\mathrm{min}$ stimulus trials and $131-\mathrm{min}$ eyes-closed trials. Ss were divided into two groups; Group 1 saw the block of matt black stimulus first and Group 2 saw the block of patterned stimulus first. Onset and termination of each trial were marked automatically on the record. Integrated output values were obtained for all Ss for all three conditions and reduced to three mean values per $S$ as follows: for eyes closed, the mean of the sum of alternate 5 -sec epochs for the last 12 eyes-closed trials only; and for the visual displays, the mean of the sum of all 5-sec epochs. This gave an equivalent time sample for all three viewing conditions.

\section{RESULTS}

Group means for the three viewing conditions are shown in Fig. 1. Three sets of comparisons were made (Wilcoxon matched pairs, signed ranks, Siegel, 1956): (a) eyes-open (the combined mean of the two eyes-open conditions) against eyes-closed; (b) eyes-open (patterned stimulus) against eyes-open (plain stimulus); and (c) first eyes-closed trial against last eyes-closed trial. Mean integrated output for eyes-closed is greater for all the measured frequencies. The difference for $2-4.5 \mathrm{cps}$ is significant at the $2 \%$ level; all other differences are significant beyond the $0.5 \%$ level. Mean integrated output is the same for the patterned as against the plain stimulus in the beta range $(14.5-20 \mathrm{cps})$. All other mean integrated values are higher for the plain stimulus: $4.5-6.5 \mathrm{cps}$ and $7.5-8.5 \mathrm{cps}(2 \%) ; 8.5-9.5 \mathrm{cps}$ and $10.5-11.5 \mathrm{cps}(5 \%)$. The differences for the $2.0-4.5 \mathrm{cps}, 9.5-10.5 \mathrm{cps}$ and $11.5-14.5 \mathrm{cps}$ all fall short of the $5 \%$ level. Comparison of the first and the last eyes-closed trials shows a decrease in high alpha, $11.5-14.5 \mathrm{cps}(1 \%)$, and an increase in very low frequencies, 2.0-4.5 cps and 4.5-6.5 cps $(0.5 \%)$.

\section{DISCUSSION}

Since the onset of drowsiness or Stage A sleep is characterized by a lowering in alpha frequency and an increase in theta activity (Oswald, 1962), our procedure (in showing both these effects) appears to have had a dearousing effect on Ss. In the absence of a nontask control group, such dearousal could be attributable simply to prolonged relaxation. However, such relaxation effects can only occur (given our procedure) against the background of the repeatedly rearousing effects of the instructions to $S$ (given at the onset of each trial). Given the overall dearousing effect, the three

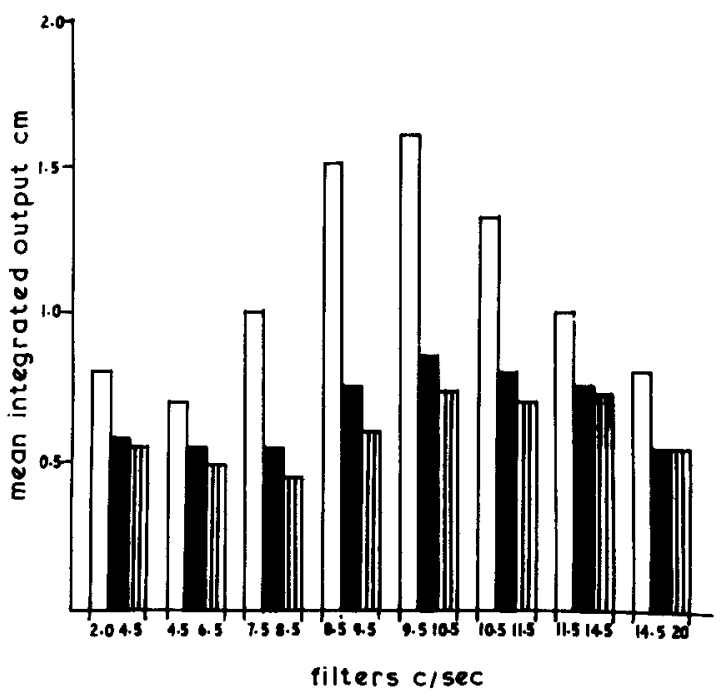

Fig. 1. Integrated output across filters for the three viewing conditions: Plain-eyes shut; Black-matt black display; Vertical line-pattemed display. 
viewing conditions do have a differential effect on integrated output. These differences may be explained in terms of an intuitive ranking of the viewing conditions along an arousal continuum, somewhat in the manner of Daniel (1965). Daniel ranks five experimental conditions on an arousal continuum (final relief from task, pretask relaxation, attention, recovery from task and task hyperventilation) and obtains a good fit with a number of parameters. Our technique is inferior to that of Daniel in that low frequency analysis confounds prevalence with amplitude and fails to measure thythmicity. Nevertheless, the results fit an arousal model.

Strictly speaking, stimulus complexity is not measured here; but rather, a comparison is made between eyes-closed, eyes-open without a stimulus and eyes-open with a stimulus. It might therefore be argued that reduced integrated output in the patterned condition is attributable to increased brightness, but this does not accord with Baker \& Franken's (1967) finding.

The differences over all filters (eyes-open against eyesclosed) support the findings of Gengerelli \& Parker (1966). They report that "when the eyes are opened and the $S$ is in a state of perceptual alertness, the amplitude in this range (8-12 cps) clearly diminishes; but there is no corresponding enhancement of the amplitude in higher frequencies." Gengerelli and Parker obtain their results with briefer exposure times than our own (18 sec only). Consideration of the EEG distribution (as shown in Fig. 1) leads one to doubt the general assumption that "desynchronization" involves a replacement of alpha activity by beta activity (Thompson, 1967). This would call for a considerable skew in the distribution. Indeed, arousal differences appear within alpha rather than in terms of a contrast between alpha and beta; beta itself is not affected differentially by the two viewing conditions (plain against patterned). Failure to obtain an effect might be due to the gross character of the beta filter, which fails to discriminate among frequencies within beta; even so, there is no difference in overall beta output for the two conditions. Again, comparison of first and last eyes-closed trials shows that the differences lie in the high alpha and subalpha ranges rather than in beta. "Desynchronization" as such is normally said to be present as a short-term response and our EEG sampling technique is designed for long-term recording. Berlyne \& McDonnell (1965) employ an alpha decrease measure rather than a beta increase measure. The absence of an effect in beta in the present study in relation to stimulus complexity (eyes-open conditions), given the association of beta with "arousal," is puzzling and merits further attention. We are undertaking further studies involving (a) a range of visual stimuli graded for complexity, and (b) an extension of the analyzer frequency range.

\section{REFERENCES}

BAKER, G., \& FRANKEN, R. Effects of stimulus size, brigh thess and complexity upon EEG desynchronization. Psychonomic Science, $1967,7,289-290$.

BERLYNE, D. E. Conflict, arousal and curiosity. New York: McGraw-Hill, 1960.

BERL YNE, D. E., CRAW, M. A., SALAPATEK, P. H., \& LEWIS, J. L. Novelty, complexity, incongruity, extrinsic motivation, and the GSR. Journal of Experimental Psychology, 1963, 66, 560-567.

BERLYNE, D. E., \& McDONNELL, P. Effects of stimulus complexity and incongruity on duration of EEG desynchronization. Electroencephalography \& Clinical Neurophysiology, 1965, 18, 156-161.

DANIEL, R. S. Electroencephalographic pattern quantification and the arousal continuum. Psychophysiology, 1965, 2, 146-160.

GENGERELLI, J. A., \& PARKER, C. E. Spectrographic analysis of electroencephalograms under conditions of alertness and relaxation. Joumal of Psychology, 1966, 63, 67-72.

OSWALD, I. Sleeping and waking. Amsterdam: Elsevier, 1962.

SIEGEL, S. Non-parame tric statistics. New York: McGraw-Hill, 1956.

THOMPSON, R. F. Foundations of physiological psychology. New York: Harper \& Row, 1967.

\section{RESULTS AND CONCLUSIONS}

Mean reading time for the 15 readers on each of the six versions (Fig. 1) supports the view that feature discriminability rather than familiarity is the critical variable in word identification. Mixing upper and lower case is disruptive when capital letters are as tall as the ascenders of the lower-case letters (Line 6), otherwise the mixture (Line 3) is as easy to read as normal type. Varying the size of alternate letters disrupts reading when the text is all lower case (Line 5), but not when it is all capitals (Line 4).

The present results cannot be attributed to "generalization of response to variations of a stimulus pattern" (whatever the assumed conditioned or canonical form might be). It is difficult to see how one could generalize among forms as diverse as hat, HAT, hat, hAt, and so forth, each of which may be far more similar to other words in the same typographic style than to the different typographic styles of the same word.

The results are consistent with other evidence that we have obtained using the same material in a comprehension-free task (Smith, Lott, \& Cronnell, in press). In the latter study, 240 Ss were required to search for target words in texts set in the different type mixes.

The most surprising outcome of the present study is perhaps not the fact that the most difficult version took $25 \%$ longer to read than the easiest. What is remarkable is the facility with which even the most bizarre passages were read. Adaptation to these mutilated texts was almost instantaneous, the number of words read in the first $10 \mathrm{sec}$ correlating highly with the speed

\section{page 261$)$}

ot reading the entire passage. Our daily experience is that quite unfamiliar handwriting becomes relatively legible once we have "cracked the code" of a few words, i.e., established a sample of feature equivalences. One of the most important skills of the fluent reader may be that of acquiring and mastering a wide variety of functional equivalences for a diversity of typographic and calligraphic forms. Familiarity with any particular form is irrelevant.

\section{REFERENCES}

ANDERSON, I. H., \& DEARBORN, W. F. The psychology of teaching reading. New York: Ronald Press, 1952.

GIBSON, E. J. Learning to read. Science, 1965, 148, 1066-1072.

POSTMAN, L, \& ROSENZWEIG, M. R. Practice and transfer in the visual and auditory recognition of verbal stimuli. American Journal of Psychology, 1956, 69, 209-226.

SIEGEL, S. Nonparametric statistics for the behavioral sciences. New York: McGraw-Hill, 1956.

SMITH, F. The use of featural dependencies across letters in the visual identification of words. Journal of Verbal Learning \& Verbal Behavior, in press.

SMITH, F., LOTT, D., \& CRONNELL, B. The effect of type size and case alternation on word identification. American Journal of Psychology, in press.

WOODWORTH, R. S., \& SCHLOSBERG, H. Experimental psychology. New York: Holt, Rinehart, \& Winston, 1954.

\section{NOTES}

1. Research was conducted pursuant to a contract between the Southwest Regional Laboratory and the United States Office of Education. I thank Deborah Lott and Bruce Cronnell for valuable assistance.

2. Now at The Ontario Institute for Studies in Education, 102 Bloor Street West, Toronto 5, Ontario, Canada. 